\title{
WHERE DO OUR CHILDREN LEARN TO SMOKE?
}

\author{
Drahoslava Hrubá1, Iva Žaloudíková ${ }^{2}$ \\ ${ }^{1}$ Department of Preventive Medicine, Faculty of Medicine, Masaryk University, Brno, Czech Republic \\ ${ }^{2}$ Department of Psychology, Faculty of Education, Masaryk University, Brno, Czech Republic
}

\begin{abstract}
SUMMARY
Background: Primary prevention of smoking in children is mostly carried out through school education schemes organised by trained teachers. The generally accepted notion is that children's opinions and behaviour are influenced by the school, but mainly by the family and their peers, as well as by the broader society. The primary preventive programme aimed at the first three years of primary schools, called "No Smoking is a Norm" strives to encourage parents to take an active part in the education of their children against smoking, as well as about other aspects of a healthy lifestyle. This paper analyses the data documenting the effectiveness of the programme with respect to children's family smoking history.

Methods: The information about smokers in families was collected during enquiries prior to the initiation of the 1st and 2nd stage (in the 1st and the 2nd class), and again after their conclusion. In the first stage, smoking of mothers, fathers, and grandparents was followed separately. In the second stage, the category of smokers that can influence children, included parents, grandparents, siblings, aunts, and uncles, with whom the children are in contact (the so-called "broader family"). Questionnaires answered by children who did not know whether their parents or grandparents smoked were excluded from the survey. The analysis included 1,423 (i.e. 76.6\%) from the total number of 1857 children from the programme and control groups. The answers were coded and analysed using the $x^{2}$ test in EPI INFO software, version 3.3.2.

Results: Approximately $30 \%$ of the children's parents are smokers. Almost $60 \%$ of the children were exposed to the influence of smoking parents and grandparents, and more than three quarters of the children experienced smoking from the "broader family". The more smokers there are in the family, the more children have the opportunity to handle cigarettes and smoking accessories from an early age: they get, buy, or even light cigarettes. Smoking of parents and other relatives led to a substantial increase in the number of children who were determined to smoke in the future or were considering it. More than half of the eight-year-olds have tasted an alcoholic drink, and significantly more frequently in the families of smokers. $8 \%$ of the eight-year-olds have gone through their first smoking attempts and all of them from families with adult smokers. On the other hand, the smoking or non-smoking family environment of the respondents did not influence the knowledge part of the intervention programme. In the study group, in comparison with the control group, there were significantly more children exposed to the influence of smokers in the "broader" family (80.1\% vs. $73.0 \%)$. This could explain why evaluation of the medium-term efficiency of the programme without consideration of the family environment was highest in the knowledge area, while differences in change of opinions and behaviour were mostly insignificant.

Conclusions: Smoking of family members significantly reduces the efficiency of school educational anti-smoking activities aimed at children and young people.
\end{abstract}

Key words: school children, smoking families, educational programme

Address for correspondence: D. Hrubá, Department of Preventive Medicine, Masaryk University, Komenskéno nám. 2, 66243 Brno. E-mail: hruba@med.muni.cz

\section{INTRODUCTION}

The modern primary prevention programmes aimed at nonsmoking are oriented to increase children's knowledge about the health risks of smoking, as well as to influence their opinions on desirable - i.e. non-smoking - behaviour (1). When assessing the efficiency of individual programmes, the questions in the checklist questionnaires are formulated in order to evaluate the influence on these three main aims. In the usual method of assessing programme efficiency on knowledge, opinions, and behaviour, the answers of children influenced by the programme are compared to the answers of children from a control group: the investigation is carried out prior to the launching of the programme, after its end, and possibly also in other terms enabling determination of time during which the impact of the programme is still evident.

The children's education is mostly carried out through school programmes, which are organised by trained teachers. The generally accepted notion is that the children's opinions and behaviour are influenced not only by the school, but mainly by the family and their peers, as well as the broader society. The family environment, in particular, is crucial for the formation of children's opinions and behaviour in their youth, as well as later, when peer pressure gradually grows stronger. Many older and recent foreign studies have repeatedly confirmed that parents' smoking is one of the most important factors influencing the first smoking attempts of children (2-8).

More frequent smoking attempts, as well as regular smoking in eleven-year-olds from smoking families were confirmed also in the Czech population: in the cohort of approximately 10,000 children the frequency of smokers was significantly higher if they had a smoking mother. There was a substantially greater influence from smoking siblings and friends. The same study proved that parents' smoking also influences if their children choose smokers or non-smokers as friends (9).

This is why both foreign and Czech primary prevention programmes aim to attract the parents and win them over for active co-operation. It has to be said that this effort, striving to create co-operation between the school and family, is usually more or less ineffective, and parents' co-operation is often rather sporadic. 
The primary prevention programme aimed at the first three years of primary school, called "No Smoking is a Norm" also supports the active participation of parents by various means: the parents receive written reports about the contents of the programme in each of its stages. They are requested to co-operate on certain "homework", and are asked for their comments and evaluation of the programme through anonymous questionnaires. In a special brochure called "How to make sure your child does not smoke" the parents receive detailed information about the risks of passive smoking on children's health, about the importance of the model role of adult smokers for future smoking of children, as well as advice on how to talk with children about smoking.

The individual stages in the programme are monitored through pre-tests (one month before launching of the programme in the given school class) and post-tests (4-5 months after the last of five lessons of each year); the pre-tests carried out in the 2nd and 3rd class also serve as sources of information on the longterm effect of the previous stage. Considering the very low age of involved children (6-9 years), the method of data collection used a combined structured interview with each child (a system of open and closed questions), complemented with a drawing of "Paint what is healthy". A similar method was also used in foreign studies (10). Besides classes in which the programme is applied, there are control classes studied in the same way - with peers from the same schools or schools where the programme is not used at all. This work analyses the data gained from one another point of view - whether the children come from a smoking or non-smoking family.

\section{METHODS}

Information about smokers in the family was gathered during the pre-test and post-test analyses prior to the launching of the 1 st and 2nd stage, and again after their conclusion in post-tests. The initial analysis in the first stage studied separately smoking of the mother, father, and grandparents. In the second stage, the category of smokers included parents, grandparents, and also siblings, aunts, and uncles, with whom the children are in contact (the so-called "broader family").

Due to the fact that in the first analysis prior to the launching of the 1st stage the children in the control and programme groups did not differ in knowledge, opinions, and behaviour, and the data evaluating the frequency of selected signs according to smoking in the family was processed for both groups, the control and the programme one. Questionnaires answered by children who said they did not know whether their parents and grandparents smoked or not were excluded from the evaluation. The analysis included 1,423 (i.e. $76.6 \%$ ) from the total number of 1,857 children from the control and the programme groups.

The influence of intervention in the first and second stage of the "No Smoking is a Norm" programme was monitored by comparing the data from pre-tests and post-tests of the 1st and 2nd stage only from the intervened cohort: 1,057 (pre-test 1), 813 (post-test 1), 990 (pre-test 2), 611 (post-test 2) children respectively. Because some teachers did not respect the specific methods for obtaining data, only correct questionnaires were included into the analysis; it explains the different numbers of children in follow-up measurement. In this evaluation, only data of children from non-smoking and smoking families were compared without a more detailed distinction of whether there are only one or more smokers in the family.

The children's answers, as well as their drawings, were coded and analysed using the $\chi^{2}$ test in the EPI INFO programme, version 3.3.2.

\section{RESULTS}

Almost 30\% of the children's parents are smokers. In almost $10 \%$ of these cases, both mother and father smoke. One fifth of the children have no-smoking parents, but their grandparents smoke, and in another almost $10 \%$ both parents and grandparents are smokers; thus almost $60 \%$ of the children are exposed to the influence of smoking parents and grandparents. If the group of adults, who could act as an example of bad behaviour for children, includes also other relatives with whom the child is in contact and whose behaviour he/she observes (his/her older siblings, aunts, uncles), more than three quarters of all children are exposed to smoking (Table 1).

Table 1. Children's exposure to smoking of relatives (percent of exposed together from the "programme" and "control" groups)

\begin{tabular}{|c|c|c|}
\hline Smoking & No. of exposed & $\%$ \\
\hline Only grand-parents ${ }^{1}$ & 309 & 21.7 \\
\hline Only parents ${ }^{1}$ & 401 & 28.2 \\
\hline Only mother ${ }^{1}$ & 54 & 3.8 \\
\hline Only father $^{1}$ & 210 & 14.8 \\
\hline Both parents ${ }^{1}$ & 137 & 9.6 \\
\hline Both parents and grand-parents 1 & 132 & 9.3 \\
\hline Together exposed in families ${ }^{1}$ & 842 & 59.2 \\
\hline Living in non-smoking families ${ }^{1}$ & 581 & 40.8 \\
\hline $\begin{array}{l}\text { Exposed in the "wider families"2 } \\
\text { (siblings, aunts, uncles included) }\end{array}$ & 756 & 76.4 \\
\hline With no family exposure ${ }^{2}$ & 234 & 24.6 \\
\hline
\end{tabular}

Notice: ${ }^{1}=$ data from the pre-test in the 1 st grade ${ }^{2}=$ data from the pre-test in the 2nd grade

Smoking or non-smoking of parents did not influence the knowledge of children about the health risks of smoking: almost all of them (98\%) confirmed that smoking damages health. More than half of them (53\%) knew that smoking causes lung diseases, $46 \%$ stated that smoking causes cancer, and 45\% knew about heart damage, $15 \%$ linked smoking to dental problems, and $17 \%$ to other diseases. The small differences in the frequency of answers of children from smoking and non-smoking families were statistically insignificant.

When asked how they liked smoking of girls/women and boys/ men, children usually gave critical answers, marking such behaviour with " 5 " or " 4 " on a five-point scale. Data collected prior to the launching of the programme show that more critics came from non-smoking families: $97 \%$ dislike smoking of women, while $95.7 \%$ criticise smoking of men. The more smokers there 
were in the family, the less criticism from the children. In families where both parents and grandparents were smokers, smoking of women, and of men, was criticised by significantly less children (90.8\%, 84.6\% resp., $\mathrm{p}<0.001)$. All groups were more critical to smoking of women than of smoking of men $(p<0.01)$.

In the programme group, critical opinions of children on smoking of adults developed in various directions: in children from non-smoking families, there were substantially more critics of both smoking men and women. On the other hand, in the group of children from smoking families the number of critics of men's smoking remains the same, and there are even less who criticise women smokers (Table 2).

Table 2. Trends in critical attitudes to the adults' smoking in the "programme" group of children (per cent)

\begin{tabular}{|l|c|c|c|c|c|c|}
\hline Etape & \multicolumn{5}{|c|}{ Children from families with } \\
\hline $\begin{array}{l}\text { Criticism of } \\
\text { smoking }\end{array}$ & \multicolumn{2}{|c|}{ non-smokers } & \multicolumn{3}{c|}{ smokers } \\
\hline & women & men & No. & women & men & No. \\
\hline $\begin{array}{l}\text { Pre-test } \\
\text { 1st grade }\end{array}$ & 96.1 & 94.9 & 423 & 95.7 & 90.6 & 634 \\
\hline $\begin{array}{l}\text { Post-test } \\
\text { 1st grade }\end{array}$ & 96.9 & 96.5 & 325 & 94.3 & 92.0 & 488 \\
\hline $\begin{array}{l}\text { Pre-test } \\
\text { 2nd grade }\end{array}$ & 96.2 & 94.9 & 234 & $93.7^{\star}$ & 91.4 & 756 \\
\hline $\begin{array}{l}\text { Post-test } \\
\text { 2nd grade }\end{array}$ & 98.7 & $98.1^{\star \star}$ & 155 & $94.9^{\star}$ & 90.0 & 456 \\
\hline
\end{tabular}

Notice: For the statistic significance, the data obtained in the 1st grade pre-test were the refferent values: ${ }^{*}=p<0.05,{ }^{* *}=p<0.01$

Table 3. Availability of tobacco products for children (data from pre-test at the 1st grade, per cent of answers from subgroups of children different by their exposure in family)

\begin{tabular}{|l|c|c|c|}
\hline \multirow{2}{*}{ Smokers in family } & \multirow{2}{*}{$\begin{array}{c}\text { No. of } \\
\text { children }\end{array}$} & \multicolumn{2}{|c|}{ Tobacco/cigarettes } \\
\cline { 3 - 4 } & 581 & 1.4 & 1.0 \\
\hline Nobody & 309 & $6.1^{\star \star \star}$ & $3.6^{\star \star}$ \\
\hline Only grand-parents & 210 & $7.6^{\star \star \star}$ & 2.4 \\
\hline Only father & 54 & $9.3^{\star \star *}$ & $14.8^{\star \star \star}$ \\
\hline Only mother & 137 & $15.3^{\star \star \star}$ & $16.1^{\star \star \star}$ \\
\hline Both parents & 132 & $17.4^{\star \star *}$ & $18.2^{\star \star \star}$ \\
\hline $\begin{array}{l}\text { Both parents and } \\
\text { grand-parents }\end{array}$ & & lighted up \\
\hline
\end{tabular}

Notice: For the statistic significance, the data obtained about children from nonsmoking families were the refferent values: ${ }^{*}=p<0.05,{ }^{* *}=p<0.01,{ }^{* * *}=p<0.001$

From the children's answers it was clear that in the smoking families children of pre-school or early school age have easier access to cigarettes: they bring or buy them for smokers and are even asked to light them. The more smokers there are in the family the bigger the chance to handle cigarettes from a very early age, to learn the skills relating to the "ceremony" of smoking (Table 3). The programme led to a decrease in the number of children handling cigarettes in non-smoking families - no child from this group had access to cigarettes afterwards. Children, whose parents or grandparents do not smoke, hardly ever meet smokers, usually on occasional visits only. On the other hand, in families where adults smoke, the programme completely failed in this aspect. During repeated analyses at the end of the 1st class and in the 2nd class, the number of children handling cigarettes increased substantially: bringing/buying of cigarettes at the end of the 2nd class in comparison with the beginning of the 1 st class was reported by $4.7 \%$ more children (total 13.9\%), 7.1\% more children (total 12.0\%) $(\mathrm{p}<0.01)$ tried lighting cigarettes in the same period.

The influence of smokers in the family is reflected also in the opinions of 7-8-year-olds about their future smoking behaviour. If the children had non-smoking parents and only grandparents smoked, they did not differ in the decision about future smoking from children of non-smokers. But smoking of parents and the broader family substantially increased the number of children who were determined to or thinking about smoking in the future (Table 4).

Table 4. Children's believes about their future smoking (data from the pre-tests 1 and 2, and post-test 2, per cent of answers from subgroups of children different by their exposure in family)

\begin{tabular}{|l|c|c|c|c|}
\hline \multirow{2}{*}{ Smokers in family } & \multirow{2}{*}{$\begin{array}{c}\text { No. of } \\
\text { children }\end{array}$} & \multicolumn{3}{|c|}{ Smoking in future } \\
\cline { 3 - 5 } & 581 & 1.0 & 5.2 & 93.8 \\
\hline Nobody PRE1 & 309 & 1.6 & 3.6 & 94.2 \\
\hline $\begin{array}{l}\text { Only grand- } \\
\text { parents PRE1 }\end{array}$ & 210 & $4.3^{\star \star}$ & $14.3^{\star \star \star}$ & $81.4^{\star \star \star}$ \\
\hline Only father PRE1 & 54 & $7.4^{\star \star \star}$ & $9.3^{\star}$ & $83.3^{\star \star}$ \\
\hline Only mother PRE1 & 137 & $5.1^{\star \star}$ & $19.7^{\star \star \star}$ & $72.5^{\star \star \star}$ \\
\hline Both parents PRE1 & 132 & $6.1^{\star \star \star}$ & $13.6^{\star \star \star}$ & $80.3^{\star \star \star}$ \\
\hline $\begin{array}{l}\text { Both parents and } \\
\text { grand-parents) } \\
\text { PRE1 }\end{array}$ & 756 & $14.7^{\star \star \star}$ & 4.1 & $81.2^{\star \star \star}$ \\
\hline "Wider family" PRE2 & 456 & 1.5 & $16.7^{\star \star \star}$ & $81.8^{\star \star \star}$ \\
\hline $\begin{array}{l}\text { "Wider family" } \\
\text { POST2 }\end{array}$ & & & & No \\
\hline
\end{tabular}

Notice: For the statistic significance, the data about children from non-smoking families were the refferent values: ${ }^{*}=p<0.05,{ }^{\star \star}=p<0.01,{ }^{\star \star \star}=p<0.001$

The programme also influenced children living in families with no smokers: after the first stage of the programme, many of those who were not sure about smoking in the future (5.0\%) tended to incline to the opinion that they would not smoke in the future. The number of future non-smokers in this group increased from $93.8 \%$ to $96.9 \%(\mathrm{p}<0.05)$, and the number of potential future smokers remained unchanged (steady around $1.2 \%$ ).

The opposite trend is apparent in the group of children from smoker families, where the number of future non-smokers remains relatively stable during the monitored period (around 82\%), whereas most of the hesitant ones from the 1st analysis (14.4\%) later opted for the alternative of becoming smokers (post 1 and pre 2): the frequency of "future smokers" increased from 3.3 to $14.7 \%$ $(p<0.001)$. However, in the final test after the end of the 2nd stage (post 2), the group of children from smoker families inclined to a promising development, i.e. a new shift, this time of the originally "determined" future smokers into the "hesitant" group; in this analysis, $1.7 \%$ of children from smoker families wanted to smoke 
in the future, which is less than during the initial analysis prior to the programme. If this trend were to remain through to the next period, the efficiency of the programme would be very good.

Unfortunately, 8\% of eight-year-olds have already gone through their first smoking attempts, and with few exceptions (3 children) they all come from families where some of the adults smoke. Also the findings relating to the access of children to alcohol are alarming: $47 \%$ from non-smoker and $62 \%$ from smoker families already had the opportunity to taste an alcoholic drink (beer or wine); the number of such children was significantly higher in smoking families $(\mathrm{p}<0.001)$.

\section{DISCUSSION}

Some authors of primary prevention anti-smoking programmes wonder why they are not as successful as originally expected, or why the success of the same programme differs in various locations. In general, there are three factor groups that are responsible for the lower efficiency: imperfect implementation of the programme, socio-cultural conditions, and individual characteristics of the children that influence their interaction with the contents and forms of the programmes (11).

This study confirmed the presumption of the significant role of the family in the process of forming opinions on smoking and active behaviour in very young children, pupils from the first class of primary schools. Children watch their smoking relatives and the situations when they light cigarettes, how they inhale the smoke, and what they do with the ash. Because of their strong emotional relation to these smokers in the family, the children form positive attitudes to smoking behaviour from a very early age. The results are even more serious due to the fact that most of the children monitored by us have smokers among their closest relatives - parents or grandparents.

Although the sample of children taking part in the study was not selected representatively but based on the voluntary involvement of the teachers wanting to test a new anti-smoking educational programme, the data from children came from several regions: big cities, regional towns, small towns, and villages. This leads to the premise that the presented data would not be very different from the reality in the Czech Republic in general. A similar prevalence of children exposed to the influence of smoking in the family environment was detected also by the authors of the Teplice-Prachatice study (12).

The work could contribute also to methodological practice: it is possible to recommend consideration of the family environment of the respondents for the evaluation of the efficiency of school anti-smoking intervention programmes. This does not affect the knowledge part of the intervention programme; children are able to accept or interpret knowledge gained at school or in another way. But they are not able to use their knowledge about the health risks of smoking to form opinions on this behaviour; here, the influence of family is an example of strong emotional relations which are decisive for formation of future children's behaviour.

More detailed data gathered at the beginning of the 2nd stage has shown that the programme group, in comparison with the control one, contained significantly more children exposed to the influence of smokers in the "broader" family (80.1\% vs. $73.0 \% ; \mathrm{p}<0.01$ ). This could add to the explanation of why the medium-term efficiency of the programme without consideration of the family background has mostly demonstrated in the area of knowledge, whereas changes in behaviour and opinions were mostly insignificant (13).

\section{CONCLUSIONS}

Even though it is clear that the discrepancies between school and family education substantially weaken the efficiency of primary preventive programmes, this specific form of health education should not be ignored and abandoned completely. Quite the opposite - the importance of school in the education of children about a healthy lifestyle increases with worsening of the situation of the family and the entire society in this aspect. Further development of similar programmes should stress the necessity of variable approaches according to the characteristics of the targeted group of children to be educated, or a multiple stage approach could be prepared and applied (14).

\section{Acknowledgements}

The study was supported by Programme PPZ MZ ČR No. 9729, League against Cancer Prague, and the Research Project MŠMT No. 0021622421.

\section{REFERENCES}

1. Glynn TJ. Essential elements of school-based smoking prevention programs. J Sch Health. 1989 May;59(5):181-8.

2. Bricker JB, Peterson AV, Robyn Andersen M, Leroux BG, Bharat Rajan K, Sarason IG. Close friends', parents' and older siblings' smoking: reevaluating their influence on children's smoking. Nicotine Tob Res. 2006 Apr;8(2):217-26

3. Bricker JB, Peterson AV Jr, Leroux BG, Andersen MR, Bharat Rajan K, Sarason IG. Prospective prediction of children's smoking transitions: role of parents'and older siblings'smoking. Addiction. 2006 Jan;101(1):128-36.

4. Conrad KM, Flay BR, Hill D. Why children start smoking cigarettes: predictors of onset. Br J Addict. 1992 Dec;87(12):1711-24.

5. Griesbach D, Amos A, Currie C. Adolescent smoking and family structure in Europe. Soc Sci Med. 2003 Jan;56(1):41-52.

6. Covey LS, Tam D. Depressive mood, the single-parent home, and adolescent cigarette smoking. Am J Public Health. 1990 Nov;80(11):1330-3.

7. O’Loughlin J, Paradis G, Renaud L, Sanchez Gomez L. One-year predictors of smoking initiation and of continued smoking among elementary schoolchildren in multiethnic, low - income, inner-city neighbourhoods. Tob Control. 1998;7(3):268-75.

8. Swan AV, Creeser R, Murray M. When and why children first start to smoke. Int J Epidemiol. 1990 Jun;19(2):323-30.

9. Hrubá D. Passive smoking and its influence on schoolchildren's behaviour. Prakt Lék. 1996 Oct;76(10):517-20. (In Czech.)

10. Oakley A, Bendelow G, Barnes J, Buchanan M, Husain OA. Health and cancer prevention: knowledge and beliefs of children and young people. BMJ. 1995 Apr 22;310(6989):1029-33. Erratum in: BMJ 1995 May 13;310(6989):1231.

11. Johnson CA, Cen S, Gallaher P, Palmer PH, Xiao L, Ritt-Olson A, at al. Why smoking prevention programs sometimes fail. Does effectiveness depend on sociocultural context and individual characteristics? Cancer Epidemiol Biomarkers Prev. 2007 Jun;16(6):1043-9.

12. Dostál M, Milcová A, Binková B, Kotěšovec F, Nožička J, Topinka J, et al. Environmental tobacco smoke exposure in children in two districts of the Czech Republic. Int J Hyg Environ Health. 2008 Jul;211(3-4):318-25.

13. Žaloudíková I, Hrubá D. Educational preventive programme for younger schoolchildern, “It’s normal not to smoke”. Pedagogika. 2006;56(3):24657. (In Czech.)

14. McKinlay J, Marceau L. US public health and the 21st century: diabetes mellitus. Lancet. 2000 Aug 26;356(9231):757-61.

Received March 21, 2008 Accepted in revised form August 25, 2008 